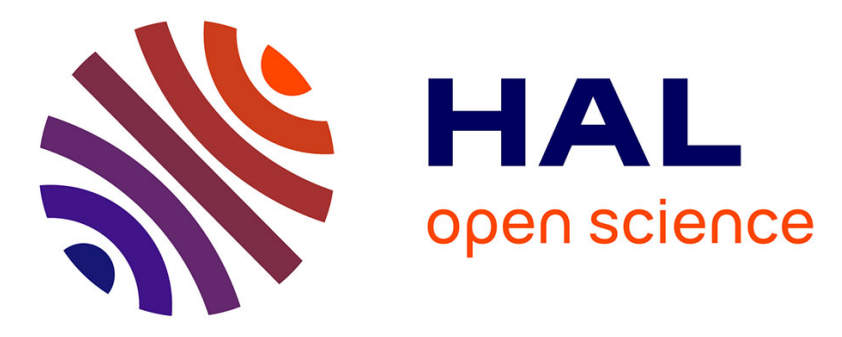

\title{
Technique for Reducing the Power Supply in Reconfigurable Cylindrical Electromagnetic Band Gap Structures
}

\author{
Halim Boutayeb, Tayeb Denidni
}

\section{- To cite this version:}

Halim Boutayeb, Tayeb Denidni. Technique for Reducing the Power Supply in Reconfigurable Cylindrical Electromagnetic Band Gap Structures. IEEE Antennas and Wireless Propagation Letters, 2006, 5 (1), pp. 424-425. 10.1109/LAWP.2006.883951 . hal-00149263

\section{HAL Id: hal-00149263 https://hal.science/hal-00149263}

Submitted on 25 May 2007

HAL is a multi-disciplinary open access archive for the deposit and dissemination of scientific research documents, whether they are published or not. The documents may come from teaching and research institutions in France or abroad, or from public or private research centers.
L'archive ouverte pluridisciplinaire HAL, est destinée au dépôt et à la diffusion de documents scientifiques de niveau recherche, publiés ou non, émanant des établissements d'enseignement et de recherche français ou étrangers, des laboratoires publics ou privés. 


\title{
Technique for Reducing the Power Supply in Reconfigurable Cylindrical Electromagnetic Band Gap Structures
}

\author{
Halim Boutayeb and Tayeb A. Denidni
}

\begin{abstract}
In this letter, a new design of Cylindrical Electromagnetic Band Gap (CEBG) structures is proposed in order to reduce the power supply used to control active elements in EBG-based reconfigurable antennas. The proposed configuration uses structures of discontinuous wires with defects consisting of continuous wires. To examine its performances, numerical simulations were carried out using a Finite Difference Time Domain (FDTD) code, for the structure without active elements. The obtained results show that the new configuration allows to obtain a directive beam in the pass-band of the all continuouswires structure. This work has potential application for designing an antenna with a directive pattern able to turn over $360^{\circ}$ range.
\end{abstract}

Index Terms-Periodic structures, cylindrical structures, reconfigurable materials

\section{INTRODUCTION}

D IFFERENT methods have been proposed for designing agile antennas. For instance, mechanical steerable-beam systems have been proposed, but they are easily deteriorated and their maintenance is too complex. Another solution to modify the radiation pattern consists on using smart antennas, such as adaptive antenna arrays [1] or phased arrays [2]. However, the cost of smart antennas is high, and these technologies lead often to complex designs. As an alternative to conventional beam switching systems, reconfigurable Electromagnetic Band Gap (EBG) materials [3, 4] can be used.

To obtain a directive pattern being able to turn over $360^{\circ}$ range, Cylindrical EBG (CEBG) structures present an attractive solution $[5,6]$. The technique proposed in $[5,6]$ consists on using a cylindrical EBG structure constituted of discontinuous wires with active elements. The beam switching is obtained by creating defects consisting of discontinuous wires in an initial continuous-wire structure. The inconvenient of this design is that it necessitates an important power supply DC current to control the active elements.

To reduce the required power for controlling the active elements in reconfigurable CEBG-based antennas, this paper proposes a new design. The proposed configuration is based on a discontinuous-wire CEBG structure with defects consisting of continuous wires. The transmission coefficients of structures with all continuous or discontinues wires are used for the design. Then, Finite Difference Time Domain (FDTD) results for

Manuscript received May 1, 2006, revised July, 26, 2006. This work was supported by NSERC.

Halim Boutayeb and Tayeb Denidni are with INRS-EMT, 800 de la Gauchetiere ouest, Montréal, H5A 1K6, Canada, boutayeb@emt.inrs.ca. the radiation patterns of the proposed configuration, without active elements, are presented and discussed.

\section{CylindricAl EBG STRUCTURES CharaCterization}

A Cylindrical EBG structure as shown in Fig. 1 is considered. To calculate the transmission coefficient of this structure, the characteristics of a single cylindrical Frequency Selective Surface (FSS) are first calculated, and then a cascading approach is applied [6]. The transmission coefficient is calculated by considering cylindrical incident and transmitted waves.

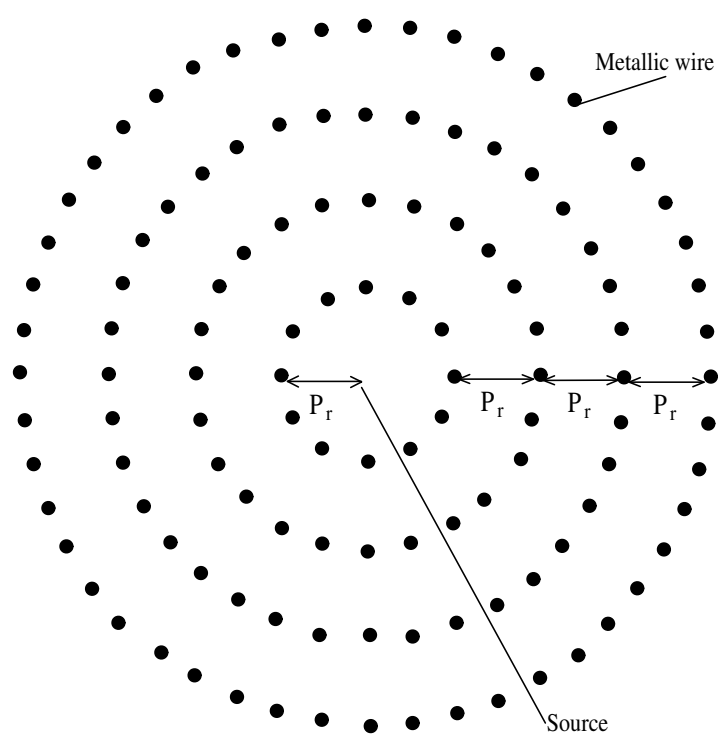

Fig. 1. Cylindrical Electromagnetic Band Gap (CEBG) structure composed of multiple layers of cylindrical FSSs with metallic wires.

Figure 2 presents the calculated magnitude of the transmission coefficient for four layers of cylindrical shells with the two cases: continuous wires and discontinuous wires. For the discontinuous wire case, the finite wires are $L_{w}=18 \mathrm{~mm}$ length, and the vertical distance between two wires is $w=2 \mathrm{~mm}$. The CEBG structures have the following parameters: $P_{r}=45 \mathrm{~mm}$ and $a=1.5 \mathrm{~mm}$. From Fig. 2, the two structures have the dual behaviour in their pass-band and stop-band characteristics in two bands $(\mathrm{DC}-2.2 \mathrm{GHz}$ and $2.6 \mathrm{GHz}-3.2 \mathrm{GHz})$.

In the next section, a new design for reconfigurable-pattern antennas is presented. This design is based on a structure with discontinuous and continuous wires. The operating band is $2.6 \mathrm{GHz}-3.2 \mathrm{GHz}$, where the structure with all discontinuous 
wires presents a stop-band, whereas the structure with all continuous wires presents a pass-band (see Fig. 2).

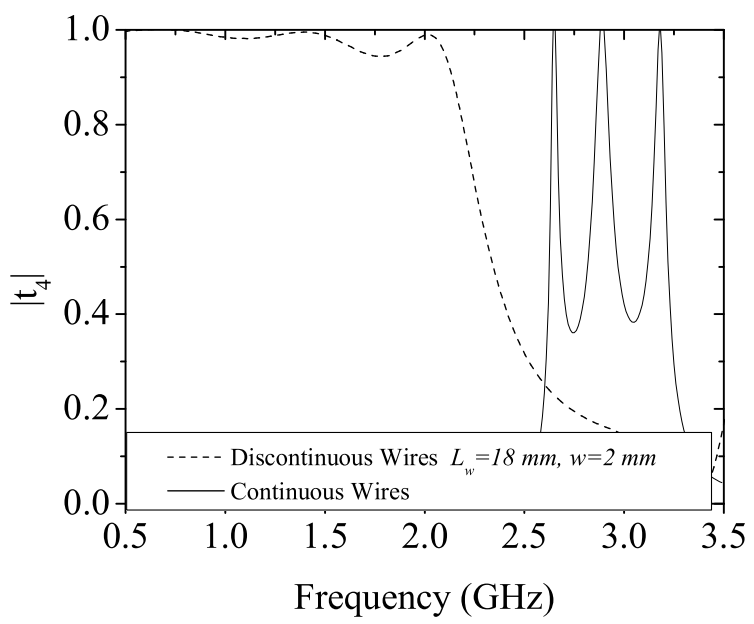

Fig. 2. Transmission coefficients for two structures with four layers of cylindrical FSSs with discontinuous or continuous wires.

\section{CEBG STRUCTURE USING DEFECTS With CONTINUOUS WIRES}

In this section, a new structure, which can be used for designing antennas with a reconfigurable beam, is proposed and tested with a FDTD code. The new configuration is presented in Fig. 3, where defects are made by continuous wires. The wire diameter $(a)$, the radial period $\left(P_{r}\right)$ and the parameters of the discontinues wires $\left(L_{w}\right.$ and $\left.w\right)$ are the same than previously. The structure is considered infinite in the vertical direction. A current line source, placed in the center, is used as an excitation.

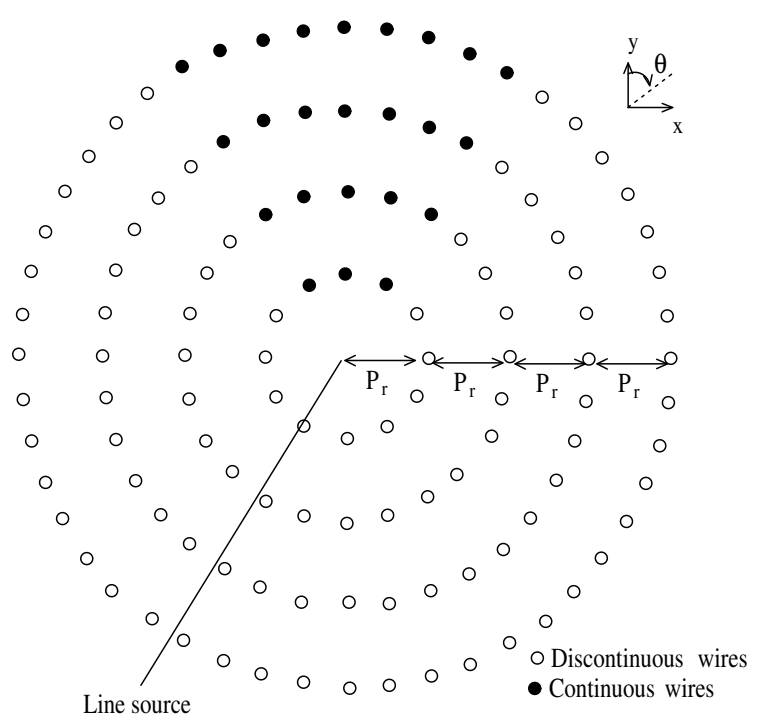

Fig. 3. CEBG structure composed of discontinuous wires using defects with continuous wires. The structure is excited by a line source placed in the center.
Figure 4 presents the computed radiation patterns in the $\mathrm{H}$ plane at $2.7 \mathrm{GHz}, 3 \mathrm{GHz}$, and $3.2 \mathrm{GHz}$. These frequencies belong to the band $2.6 \mathrm{GHz}-3.2 \mathrm{GHz}$, which is the passband of the all continuous wires structure as shown in Fig. 2. From these results, it can be noted that, in this band, a directive beam is obtained in the direction of the defects.

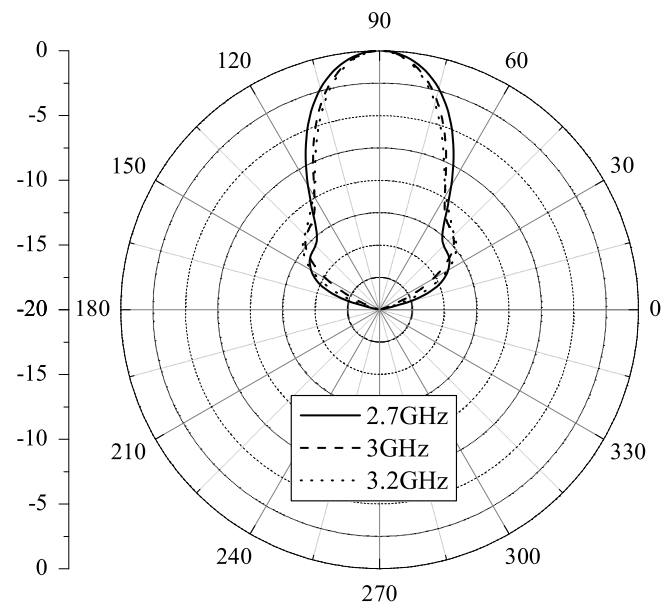

Fig. 4. Radiation patterns in the H-plane of the CEBG structure, presented in Fig. 3, at $2.7 \mathrm{GHz}, 3 \mathrm{GHz}$ and $3.2 \mathrm{GHz}$.

In the new design, the number of wires behaving as continuous wires is reduced by $75 \%$ compared to the previous design [6]. Then, in the reconfigurable structure, the number of active elements in On-state and the required power supply used for the control of the active elements will be reduced by the same percentage.

\section{CONCLUSION}

A new Cylindrical Electromagnetic Band Gap (CEBG) structure with defects, for beam-switching antennas applications, has been designed and tested numerically. This configuration uses a structure composed of discontinuous metallic wires and with defects consisting of continuous wires. The proposed solution will allow to reduce the number of active elements in On-state, in CEBG-based reconfigurable antennas, and thus will reduce the required power supply DC current.

\section{REFERENCES}

[1] R. T. Jr. Compton, Adaptive Antennas: Concepts and Performance, Englewood Cliffs, NJ: Prentice-Hall, 1988.

[2] R. J. Mailloux, Phased Array Antenna Handbook, Boston, MA: Artech House, 1994.

[3] G. Poilasne, P. Pouliguen, K. Mahdjoubi, L. Desclos and C. Terret, "Active Metallic Photonic Band-Gap materials : experimental results on beam shaper ", IEEE Trans. Ant. Prop., vol. 48, pp. 117-119, Jan. 2000.

[4] H. Boutayeb, T. A. Denidni, A. Sebak and L. Talbi, "Band structure analysis of crystals with discontinuous metallic wires", IEEE Microw. Wireless Comp. Lett., vol.15, pp. 484-486, July 2005.

[5] P. Ratasjack, T. Brillat, F. Gadot, P.Y. Garel, A. de Lustrac, H. Boutayeb, K. Mahdjoubi, A.C Tarot, and J.P. Daniel, "A reconfigurable EBG structure for a beam steering base station antenna", JINA, Nov. 2004

[6] H. Boutayeb, T.A. Denidni, K. Mahdjoubi, A.-C. Tarot, A. Sebak and L.Talbi, "Analysis and Design of a Cylindrical EBG-based directive antenna, IEEE Trans. Ant. Propag., vol.54, pp. 211-219, Jan. 2006. 